\title{
Memory impairment and source misattribution in postevent misinformation experiments with short retention intervals
}

\author{
ROBERT F. BELLI \\ Xavier University, Cincinnati, Ohio \\ D. STEPHEN LINDSAY \\ University of Victoria, Victoria, British Columbia, Canada \\ and \\ MARIA S. GALES and THOMAS T. MCCARTHY \\ Creighton University, Omaha, Nebraska
}

\begin{abstract}
The four experiments reported here provide evidence that (1) misleading postevent suggestions can impair memory for details in a witnessed event and (2) subjects sometimes remember suggested details as things seen in the event itself. All four experiments used recall tests in which subjects were warned of the possibility that the postevent information included misleading sug. gestions and were instructed to report both what they witnessed in the event and what was men. tioned in the postevent narrative. Recall of event details was poorer on misled items than on control items, and subjects sometimes misidentified the sources of their recollections. Our results suggest that these findings are not due to guessing or response biases, but rather reflect genuine memory impairment and source monitoring confusions.
\end{abstract}

The misinformation effect refers to the robust finding that subjects who receive verbal misleading postevent information after viewing an event are less accurate in reporting event details than are subjects in a control condition (E. F. Loftus, 1975, 1992; E. F. Loftus, Miller, \& Burns, 1978). Two processes hypothesized to contribute to the misinformation effect are memory impairment (Belli, Windschitl, McCarthy, \& Winfrey, 1992; Ceci, Ross, \& Toglia, 1987; Lindsay, 1990; Toglia, Ross, Ceci, \& Hembrooke, 1992) and source misattribution (Lindsay, 1990, in press; Lindsay \& Johnson, 1989, 1991; Zaragoza, Dahlgren, \& Muench, 1992). Memory impairment occurs when postevent misinformation prevents or hinders the ability to remember event details, either because the misinformation alters the stored trace of the event details or because the misinformation renders the event details less accessible. Source misattribution occurs when sub-

This research was partly supported by Public Health Service Grant MH15792 to the Department of Psychology at Vanderbilt University. Experiment 2 was reported at the 1990 meeting of the Midwestern Psychological Association. We thank a number of people who helped with the preparation of this paper in various ways. Amy Dworsky, Mark Rothmayer, T. A. Spratt, Stacey Tieszen, and David Renner assisted with the collection of data, Maria Zaragoza and Saul Kassin provided experimental materials, and Francis Bellezza, Robert Proctor, Brian Cutler, and two anonymous reviewers offered critical comments regarding earlier submissions. Correspondence should be addressed to R. F. Belli, Survey Methodology Program, Institute for Social Research, University of Michigan, 426 Thompson St., Ann Arbor, MI 48106-1248.

-Accepted by previous editor, Margaret Jean Intons-Peterson jects remember the source of the postevent misinformation to be the event. The experiments reported in this paper shed additional light on these two processes.

During the mid 1970 s and early 1980 s, the misinformation effect was generally considered as evidence for memory impairment (Bekerian \& Bowers, 1983; Christiaansen \& Ochalek, 1983; E. F. Loftus, 1975; E. F. Loftus \& G. R. Loftus, 1980; E. F. Loftus et al., 1978). However, McCloskey and Zaragoza (1985) demonstrated that processes such as misinformation acceptance (a guessing bias; see also Belli, 1989) could also account for misinformation effects in such studies.

To understand McCloskey and Zaragoza's (1985) position, consider a typical experiment. First, subjects are shown a series of slides that includes a critical event item, such as a hammer. Following the event, subjects in a misled condition are verbally misinformed that a postevent item, such as a screwdriver, was shown; subjects in a control condition are not misinformed with a postevent item. Finally, subjects are asked during testing to report what was shown in the slides. In one testing procedure, known as the standard test (E. F. Loftus et al., 1978), the critical test items require subjects to choose between the event item (hammer) and the postevent item (screwdriver). Large and robust misinformation effects have been found with this test procedure. However, although memory impairment may be at least partly responsible for fewer selections of the event item in the misled condition than in the control condition, the effect could also be due to misinformation acceptance, especially if there is imperfect memory for the event item even in the control condi- 
tion. Subjects in the control condition who do not remember the event item will guess during testing and be correct, on average, half of the time. In comparison, subjects in the misled condition who do not remember the event item (for reasons other than being misled) may remember the postevent item, accept the postevent item as accurate, and consequently select the event item less than half of the time. Thus, subjects in the misled condition will guess the event item less often than will those in the control condition. Similarly, even when subjects do remember the event detail, they may accept the postevent detail, either because they place greater confidence in its accuracy or because they are playing along with the perceived desires of the experimenter.

To control for misinformation acceptance and thereby provide the possibility of a conclusive demonstration of the existence of memory impairment, McCloskey and Zaragoza (1985) devised the modified test. The modified test requires subjects to select between the event item (hammer) and a novel item (e.g., wrench). Because the postevent item is not an option at test, subjects in both misled and control conditions who remember the event item ought to select it and reject the novel item; additionally, unlike the standard test, subjects in both conditions who do not remember the event item have an equal chance of guessing correctly. Thus, fewer selections of the event item in the misled condition than in the control condition would be compelling evidence of memory impairmentthat is, evidence that exposure to the postevent item hinders the ability to remember the event item.

A number of recent experiments using centrally or conspicuously presented event items and relatively long retention intervals ( 3 to 7 days) between the event and the test have demonstrated memory impairment effects on the modified test (Belli et al., 1992; Ceci et al., 1987; Toglia et al., 1992; but also note the null effects reported by Zaragoza, 1991, and Zaragoza et al., 1992). On the other hand, such effects on the modified test have remained elusive with event items presented in the periphery of the visual field with short (less than $30 \mathrm{~min}$ ) retention intervals (Belli, 1993; Bonto \& Payne, 1991; E. F. Loftus, Donders, Hoffman, \& Schooler, 1989; McCloskey \& Zaragoza, 1985; Zaragoza, 1987; Zaragoza, 1991). ${ }^{1}$ Taken together, this research suggests that memory impairment can be detected only in limited ideal conditions (see also Lindsay, 1990). Thus, although memory impairment has been demonstrated in the laboratory, its generalizability across conditions has been questioned.

The primary purpose of the present experiments was to discover whether memory impairment can occur with peripheral event items and short retention intervals. Experiments using these conditions and the modified test have generally not produced a misinformation effect, but this may be because the modified test and other tests that rule out the postevent option as a response (e.g., the recall test of Zaragoza, McCloskey, \& Jamis, 1987) are insensitive to certain forms of memory impairment (Belli, 1989; Chandler, 1989; Johnson \& Lindsay, 1986; Toglia et al., 1992; Tversky \& Tuchin, 1989). For example, in tests that allow postevent items as responses (e.g., E. F. Loftus et al., 1978), impairment will result if reporting the postevent item precludes access to a potentially retrievable memory of the event item. In contrast, in tests such as the modified test that do not permit reporting the postevent item, subjects who would otherwise suffer such impairment may pursue a more extensive search of memory and eventually gain access to the event item. Consistent with these ideas, E. F. Loftus et al. (1989) have shown that subjects tested with the modified test select the event item more slowly when the event detail had been the target of postevent information than when the event detail served as a control test item.

To test for the possibility of impairment with short retention intervals, we devised recall testing procedures that permit the reporting of the postevent item. Our procedures are modeled after the modified modified free recall (MMFR) test procedure developed by Barnes and Underwood (1959) in their classic interference experiment (cf. Zaragoza \& Lane, 1992). In our experiments, subjects were informed of having received inaccurate postevent information and asked to report any relevant items, including both event and postevent items, that they remembered. These instructions reduce the likelihood of misinformation acceptance and response biases; subjects know that the postevent narrative is not a totally reliable source of event information, and even if their memories for the postevent details are relatively strong, they are given the opportunity to report memories of event details as well as memories of postevent details. We expected less frequent recall of event items in the misled condition than in the control condition, which would constitute compelling evidence of memory impairment. We were also interested in documenting instances of source misattribution-that is, cases in which subjects incorrectly identify the sources of remembered items (e.g., think they had witnessed things that were merely suggested in the postevent information).

\section{EXPERIMENT 1}

\section{Method}

\section{Subjects}

The subjects were 72 introductory psychology students ( 32 men and 40 women) at Vanderbilt University who received course credit for their participation. The subjects' ages ranged from 17 to 30 years $(M=18.8)$. They were tested in groups ranging in size from 4 to 11 .

\section{Procedure}

The subjects were told at the beginning of the experiment that the study investigated whether visual or verbal modes of presentation lead to a better understanding of an event. There were three major phases to the procedure: viewing slides, reading a narrative, and taking a recall test.

Slides. The 79 color slides were the same as those originally used by McCloskey and Zaragoza (1985). Four critical event items were shown to all subjects; each critical item appeared in one slide. Each subject was shown one of the three versions of the four critical items, which consisted of a coffee jar (Folgers, Maxwell House, or Nescafe), a magazine (Glamour, Vogue, or Mademoiselle), a soft drink 
can (7-Up, Coke, or Sunkist Orange), and a tool (hammer, screwdriver, or wrench). Each version was shown to one third of the subjects. Each slide was shown for $5 \mathrm{sec}$.

Narrative. After viewing the slides, the subjects worked on an unrelated filler activity for $5 \mathrm{~min}$ and then read a detailed narrative of the event depicted in the slides. In the narrative, each subject was presented with two postevent items that contradicted critical event items: these event items will be referred to as misinformation target items. For example, if the hammer was a misinformation target item, the narrative may have misled subjects that they were shown a screwdriver. Each of the other two critical items (which were not misinformation target items) served as control items; the narrative mentioned control items in neutral terms (e.g., as a tool). Counterbalancing ensured that (1) one sixth of the subjects were exposed to each of the six possible combinations of two misinformation targets and two control items (e.g., one sixth of the subjects had coffee jars and magazines as misinformation target items, and soda cans and tools as control items), (2) each version of the critical items served as a control, a misinformation target, and a postevent item equally often, and (3) for any particular misinformation target item, each of the two remaining versions of that critical item served as the postevent item equally often (e.g., when hammer served as a misinformation target item, half of the narratives mentioned the existence of screwdriver, and the other half mentioned wrench).

The narrative was read at each subject's own pace. Immediately following the narrative, the subjects returned to working on the filler exercise until $7 \mathrm{~min}$ had passed since the introduction of the narrative. Thus, there was a 12 -min retention interval between the end of the slide series and the recall test.

Test. The recall test was introduced with detailed instructions that were presented both in writing and verbally by the experimenter. The subjects were told that the purpose of the test was to determine how well they remembered some of the objects that were shown in the slides and mentioned in the narrative. They were also informed that although the narrative was mostly accurate with respect to the slides, it provided inconsistent information concerning some of the details.

The instructions, using the example of an initial that appeared on a coffee mug in one of the slides, explained that the narrative could have provided inconsistent, consistent, or no information concerning what initial was on the mug. The subjects were then told that they would be asked to remember details (mostly brand names) of eight objects, and that the narrative had provided inconsistent information for some objects, consistent information for some, and no information for some. Their task was to write down all of the details that they remembered: if they remembered that inconsistent information had been presented in the slides and the narrative, they were to write down both of the details they remembered; if they remembered consistent information, they were to write down the same detail twice; and if they remembered one detail, they were to write that down. Additionally, the subjects were told that guessing was encouraged-to "write down anything as long as you have any slight inkling that you remember it"-but that they could leave a query blank if they had "absolutely no idea." Finally, they were instructed not to concern themselves with whether what they remembered came from the slides or the narrative, but to write down anything "on the basis of believing or feeling that you experienced it during the experiment."

Following these instructions, and in view of the eight questions, the experimenter verbally summarized the instructions, reminding the subjects that if they had an inkling of remembering (1) inconsistent information, write down both details, (2) consistent information, write the same detail twice, and (3) one detail, write it down. The subjects were also reminded that if they did not have any idea, then they did not have to write anything down.

The eight test questions were the same for all subjects. There were four filler questions: two filler questions referred to items about which the narrative had presented consistent information, and two questions referred to items about which the narrative had mentioned nothing. The remaining four critical questions asked about the two control and two misinformation target items. Each question was posed in a manner such that it was clear what aspect of each item would provide an acceptable response. As examples, the coffee jar question was, "What BRAND OF COFFEE JAR was next to the coffeepot on the file cabinet?" and the tool question was, "What TYPE OF TOOL did the man put the calculator underneath in his toolbox?"'

\section{Results and Discussion}

There was a total of 144 questions of critical objects per condition. During the scoring of responses, if the subjects did not provide any response to a question, the response was scored as blank. If the subjects provided one response, it was scored as a first response. If two responses were present, the leftmost or uppermost response was scored as the first response, with the other response scored as the second response. Table 1 presents the number of each type of item given as the first response contingent upon the type of item given as the second response (event items, postevent items [for the misled condition], guessed items that were used as event or postevent items for other subjects [possible items], guessed items that were extraneous to the experiment, or no answer). Overall, the subjects reported event items $42.0 \%(121 / 288)$ of the time and postevent items $63.9 \%(92 / 144)$ of the time.

\section{Memory Impairment}

Analyses were conducted using the number of recalls of event items, either as first or second responses, as a dependent variable. Separate correlated groups $t$ tests were performed, comparing the total number of recalls of misinformation target and control items, with subjects and items as random effects. Each subject had two opportunities to recall both misinformation targets and control items, and each of the 12 event items served as the misinformation target and the control item on 12 occasions. Recall of misinformation target items $(M=0.736, S D=$ $0.671,36.8 \%$ correct) was significantly worse than recall of control items $(M=0.944, S D=0.767,47.2 \%$ correct) according to both the subjects analysis $[t(71)=$ $1.86, p<.04$, one-tailed] and the items analysis [misinformation target, $M=4.417, S D=2.610$; control, $M=$ $5.667, S D=2.708 ; t(11)=2.80, p<.01$, one-tailed].

\section{Guessing Responses}

The results reported above are consistent with the memory impairment hypothesis, but poorer misled performance (relative to control performance) might have been the result of fewer correct guesses in the misled condition than in the control condition. Consider that the subjects might have been motivated to provide at least one response per question. In the misled condition, this task would have been more easily accomplished due to the ability to provide the postevent items as responses; consequently, there might have been more guessing in the control condition and hence greater report of event details. 
Table 1

Contingency Tables of the Number of the Types of Items Reported as First and Second Responses in Control and Misled Conditions: Experiment 1

\begin{tabular}{|c|c|c|c|c|c|c|}
\hline \multirow[b]{2}{*}{ Condition } & \multirow{2}{*}{$\begin{array}{c}\text { Second } \\
\text { Response }\end{array}$} & \multicolumn{5}{|c|}{ First Response } \\
\hline & & Event & Possible & Ext & aneous $t$ & Blank \\
\hline \multirow[t]{5}{*}{ Control } & Event & 1 & & & 1 & \\
\hline & Possible* & & 1 & & & \\
\hline & Extraneous $\dagger$ & 66 & 10 & & 14 & 51 \\
\hline & & \multicolumn{5}{|c|}{ First Response } \\
\hline & & Event & Postevent & Possible* & Extra.† & Blank \\
\hline \multirow[t]{5}{*}{ Misled } & Event & 2 & 8 & & 2 & \\
\hline & Postevent & 28 & 11 & & 1 & \\
\hline & Possible* & & 1 & & & \\
\hline & Extra. $†$ & 1 & 4 & & & \\
\hline & Blank & 12 & 64 & 1 & 3 & 6 \\
\hline
\end{tabular}

Note-Subjects provided up to two responses per question, a first response (if any) and a second response (if any). If subjects wrote the same item twice, the same item is reported as first and second responses. *Possible responses are those that would have been either event or postevent items in other conditions; provides guessing rate estimates on reporting these items when not exposed to them. †Extraneous responses are reports of items that did not serve in any conditions as event or postevent items.

In fact, there were more reports of items other than event or postevent items in the control condition $(26$, or $18 \%)$ than in the misled condition (13, or $9.0 \%$ ) (see Table 1). Thus, the misinformation effect might be explained by differential guessing between the conditions, and not at all due to memory impairment.

To assess the possibility of differential guessing, 14 men and 22 women $(M$ age $=19.2$ years $)$ participated in the exact same experimental procedure as described above, with the exception that they were not shown any of the critical event items. Instead, they were shown slides identical to the critical slides, except that the critical event details were not depicted. Recalls were scored according to the probability that they would have been correct if the subjects had been shown the event items. Thus, in the control condition, the subjects were credited .33 for responding with any one of the three versions of an event detail used in the main experiment (since, given there were three different versions, any particular version that was guessed would have matched an actually shown event item, on average, only one third of the time). In the misled condition, the subjects were credited with .5 for responding with any of the two versions of the remaining event details used in the main experiment that did not include the postevent items that had actually been presented (again, since any particular guess would have been correct only half of the time). Consistent with the guessing hypothesis, if event details had been shown, the subjects in the control condition would have had significantly more correct guesses $(7.8 \%)$ than the subjects in the misled condition $(2.8 \%)$, as tested by a subjects analysis $[t(35)=2.56$, $p<.01$, one-tailed] and by an items analysis $[t(11)=$ $1.40, p<.10$, one-tailed]. This result suggests that the misinformation effect obtained in the main experiment might have been merely an artifact of guessing.
To gain a sense of whether the misinformation effect was exclusively the result of guessing, or whether memory impairment might have also played a role, we conducted an additional analysis. The guessing data revealed that two items (Coke and hammer) accounted for most of the differences in the correct guessing rates on control and misinformation target items in the subexperiment. We removed responses to these two items, and responses to two other items (Nescafe and Mademoiselle) that were rarely recalled, ${ }^{2}$ and reanalyzed the data using only the remaining "non-guessing-biased"' items (Folgers, Maxwell House, Glamour, Vogue, 7-Up, Sunkist, screwdriver, and wrench). This subanalysis suggested the possible presence of memory impairment. Although in the guessing data there was no significant difference in percentage of correct guesses of these eight non-guessing-biased items between control $(M=4.2 \%)$ and misled $(M=4.9 \%)$ conditions $[t(35)=-0.25$, in a subjects analysis, and $t(7)=-0.35$, in an items analysis], with recalls of these eight critical non-guessing-biased event items in the original data, we still found significantly poorer recall for misinformation target items $(M=4.38, S D=2.78,36.5 \%$ correct) than for control items $(M=5.88, S D=2.10$, $49.0 \%$ correct) in an items analysis $[t(7)=2.65, p<$ .02 , one-tailed]. ${ }^{3}$

\section{Source Misattribution}

The data also reveal that the subjects experienced memory source misattributions. In the misled condition, there were 13 responses that indicated that the subjects believed they had both seen and read about either event items or postevent items. Out of a total of 53 event item responses in the misled condition, $2(3.7 \%)$ involved writing the event item twice (i.e., claiming to have read about as well as seen an event detail); out of a total of 117 postevent 
item responses in the misled condition, $11(9.4 \%)$ were reported twice (i.e., claiming to have seen as well as read about a suggested detail). The greater tendency to misattribute what was read as also having been seen than to misattribute what was seen as also having been read was not statistically significant in an items analysis $[t(3)=$ $1.88, p<.20] .^{4}$

\section{EXPERIMENT 2}

The results of Experiment 1 suggest the existence of memory impairment, but it is clear that better control over guessing is necessary to more conclusively demonstrate memory impairment. To this end, only the eight nonguessing-biased items from the subexperiment in Experiment 1 were used in Experiment 2, and the instructions did not encourage guessing.

In Experiment 2, we also sought to assess source misattribution by instructing subjects to indicate the sources of the recalled items. Although the results of Experiment 1 provided evidence of source misattribution, these responses might have been more the result of inferring that items were experienced via an incorrect source than actually remembering having experienced items in incorrect sources. By having the subjects actually indicate the sources of their memories, misattributions can be more confidently identified as memory errors.

\section{Method}

\section{Subjects}

The subjects were 77 high school students between the ages of 14 and 19 years. The study was conducted as an optional demonstration experiment in four classroom groups of approximately equal size.

\section{Procedure}

The procedure was nearly identical to Experiment 1, except for the following differences:

The slides. Two versions of each of four critical slides were used: jar of coffee (Folgers or Maxwell House), magazine (Glamour or Vogue), can of soda (7-Up or Sunkist Orange), and tool (wrench or screwdriver). Each slide was presented for $4 \mathrm{sec}$.

The narrative. The narrative only included the eight versions of critical items as possible postevent items. As in Experiment 1, the narrative presented neutral information for two event items and contradictory postevent items for another two event items. Counterbalancing ensured that all versions of critical items were used approximately equally often as event and postevent items. Before reading the narrative, the subjects were engaged in an unrelated filler activity for $5 \mathrm{~min}$; they returned to the filler task for another $10 \mathrm{~min}$ after reading the narrative before the recall test was administered.

Recall test. The test instructions made it very clear that the narrative had included misleading suggestions about details in the slide sequence. An example of the format used for the test questions was presented ("The secretary was holding an UMBRELLA. What COLOR of UMBRELLA was shown in the slides? What COLOR of UMBRELLA was mentioned in the story?'). The subjects were instructed to write the answer they remembered seeing in the slides in the blank after each slide question, to write the answer they remembered reading in the story in the blank after each story question, and to leave the answer space blank if they did not remember an answer from that source.

\section{Results and Discussion}

Contingency tables of responses to slide questions and responses to story questions for control and misinformation target items are presented in Table 2. Overall, out of the total number of opportunities to report event items, the subjects did so $12.7 \%(39 / 308)$ of the time; they reported postevent items $66.9 \%(103 / 154)$ of the time.

\section{Memory Impairment}

By an items analysis, the proportion of slide questions answered correctly was reliably greater for control items $(M=.16, S D=.11)$ than for misinformation target items $[M=.10, S D=.10 ; t(7)=6.26, p<.05]$; however, the effect fell short of significance in a subjects analysis $[S D s=.26$ and .20 , for control and misinformation target items, respectively; $t(76)=1.58, p<.06$, one-tailed]. A subjects analysis of the proportion of times that the subjects reported the event detail on either the slide question or the story question also revealed better memory for event details on control items $(M=.16, S D=.27)$ than on misinformation target items $[M=.10, S D=.20 ; t(76)=$ $1.69, p<.05$, one-tailed]. This effect was also reliable in an items analysis: Mean proportion correct was greater on control items $(S D=.11)$ than on misinformation target

Table 2

Contingency Table of Responses to Slide Questions and Story Questions for Control and Misinformation Target Items: Experiment 2

\begin{tabular}{|c|c|c|c|c|c|}
\hline \multirow[b]{2}{*}{ Items } & \multirow{2}{*}{$\begin{array}{l}\text { Source of Answer } \\
\text { to Story Question }\end{array}$} & \multicolumn{4}{|c|}{ Source of Answer to Slide Question } \\
\hline & & Slide & Story* & Other & Blank \\
\hline \multirow[t]{6}{*}{ Control } & Slide & 2 & 0 & 0 & 0 \\
\hline & Story* & 0 & 1 & 0 & 1 \\
\hline & Other & 2 & 0 & 3 & 5 \\
\hline & Blank & 20 & 8 & 13 & 99 \\
\hline & & \multicolumn{4}{|c|}{ Source of Answer to Slide Question } \\
\hline & & Slide & Story & Other & Blank \\
\hline \multirow[t]{4}{*}{ Target } & Slide & 5 & 0 & $\mathbf{0}$ & 0 \\
\hline & Story & 8 & 28 & 0 & 62 \\
\hline & Other & 0 & 0 & 4 & 4 \\
\hline & Blank & 2 & 5 & 5 & 31 \\
\hline
\end{tabular}

*These are guesses of the detail that would have been presented in the story had these been target items. 
items $[S D=.10 ; t(7)=2.42, p<.05]$. Of course, these last two effects are hard to interpret, because recall of the suggested details on story questions would reduce the probability of correctly guessing the event detail on story questions.

To determine whether there might have been a bias to guess control items more often than misinformation target items, analyses were conducted on the reports of other types of items. Extraneous responses (i.e., responses that were neither event details nor postevent details) were not significantly more common on slide questions about control items $(M=.10, S D=.20)$ than on slide questions about misinformation target items $[M=.06, S D=.20$; $t(76)=1.35, p>.15]$. This suggests that the effects reported above do not reflect differential guessing rates. Furthermore, when a recall test is used, different guessing rates for control and misinformation target items would only occur if subjects were motivated to guess when they failed to recall an answer. A comparison between the frequency of extraneous responses to slide-only filler questions and slide-and-story filler questions suggests that our subjects did not feel compelled to guess: Although the subjects correctly answered slide questions about details presented in both sources $(M=.65, S D=.31)$ more often than they correctly answered questions about details presented only in the slides $[M=.32, S D=.30$; $t(76)=6.92, p<.0001]$, the frequencies of extraneous responses (i.e., known guesses) did not differ for these two types of items $[M s=.15$ and .14 , respectively; $t(76)=0.19, \mathrm{n} . \mathrm{s}$.]. These data indicate that when the subjects did not remember seeing an answer in the slides, they chose to leave the answer blank rather than guess.

In all, the data support the memory impairment hypothesis: Recall of control items was significantly better than recall of misinformation target items, and the effect apparently was not due to differential guessing. However, it is possible that control details were recalled more often than were misinformation target details because the subjects used different response criteria for these two types of event items. Subjects who can summon only a vague recollection of an event detail may be less likely to report that detail if they also recollect the corresponding suggested detail than if they remember only the event detail itself (e.g., subjects who vaguely remember that both hammer and wrench were presented at some point in the experiment may be less likely to report hammer [the event detail] than subjects who equally vaguely recollect only hammer). This response bias account is much less plausible here than when the test allows only one response per question, but our procedure does not completely eliminate it.

Although this alternative explanation does not involve memory impairment because remembering event items is not made more difficult by misinformation, it seems reasonable to argue that such a shift in response criteria involves a genuine and interesting form of memory alteration in its own right. Such a shift does not constitute a change in "mere performance"'; rather, according to this explanation, subjects' experience when remembering an event detail is altered by their concurrent recollection of a suggested detail. Thus, although this response bias explanation does not involve memory impairment, it does imply that misleading suggestions can alter the subjective experience of remembering.

\section{Source Misattribution}

Even though the subjects were expressly warned that the narrative had included inaccurate suggestions, they quite often reported suggested details in response to questions about what they had seen in the slides. On questions concerning misinformation target items, the subjects responded with details from the story 103 times; in 33 of these cases (32\%), they indicated that they remembered seeing the suggested detail in the event itself. The subjects claimed to have seen suggested details in response to slide questions about misinformation target items $(M$ proportion $=.21, S D=.32)$ significantly more often than in response to slide questions about control items $[M=.06, S D=18 ; t(76)=3.84, p<.001]$. As can be seen in Table 2, most of the errors of commission involved the subjects' correctly reporting a suggested detail as something read in the story and incorrectly reporting it as something also seen in the slides.

There was also some indication that the subjects were more likely to misattribute details from the story to the slides than to misattribute details from the slides to the story, although the low level of recall of slide details make this comparison problematic. Unlike in Experiment 1, on misinformation targets there was no tendency for the proportion of reported postevent details erroneously attributed to the event (across subjects, $33 / 103=32 \%$ ) to be greater than the proportion of reported event details erroneously attributed to the narrative $(5 / 15=33 \%)$. We suspect that this failure to replicate simply reflects measurement error due to the small number of event details reported in the misled condition. Consistent with this idea, when the data are collapsed across misinformation target and control items, of the 39 cases in which the subjects recalled a slide detail, only $7(18 \%)$ were erroneously attributed to the story (as opposed to the $32 \%$ rate of source errors involving suggested details reported above). Thus, there is some indication in Experiment 2 that subjects are more likely to misremember something they read as something they saw than to misremember something they saw as something they read. In any case, the more important finding is that the subjects quite often claimed to have seen suggested details in the event itself.

\section{EXPERIMENT 3}

The results of Experiment 2 add further support for the memory impairment hypothesis. Even though the items used were those that did not reveal a guessing bias in the subexperiment of Experiment 1, and even though subjects (1) were warned about the presence of misleading suggestions, (2) were not required to guess, and (3) could 
report a misleading suggestion and the corresponding event detail if they remembered both, a misinformation effect was nonetheless obtained.

Although these findings support the memory impairment hypothesis, two alternative accounts remain viable. First, it is possible that, because guessing was not encouraged in Experiment 2, the subjects who were misled but who remembered the event item might have opted not to report the event item because their memory of it was too vague in comparison with their memory of the postevent item. A second possibility, which also applies to Experiment 1, is the "retention enhancement hypothesis" (Brainerd \& Reyna, 1988): Providing generic postevent information (e.g., tool) in the control condition may act as a rehearsal trial that increases the accessibility of event items during the recall test. Thus, according to the retention enhancement hypothesis, the misinformation effect is not due to hindering memory for event items in the misled condition (memory impairment) but is due to enhancing memory for event items in the control condition. Experiment 3 addresses both of these possibilities.

As in Experiment 1, the subjects in Experiment 3 were encouraged to guess. When guessing is encouraged subjects are likely to report even their most vague memories. To assess differential guessing rates, we measured guessing rates by introducing a condition in which no event items were shown. In addition, we tested the retention enhancement hypothesis by introducing a pure control condition - that is, a control condition in which the event detail was not alluded to at all in the postevent narrative.

\section{Method}

\section{Subjects}

The participants were 288 undergraduates ( 188 women and 100 men) at Creighton University who received course credit for their participation. The ages ranged from 17 to 54 years $(M=19.2)$. The subjects were tested in groups that varied in size from 2 to 12 .

\section{Procedure}

The procedure was nearly identical to that used in Experiment 1, except for the following differences:

The slides. Each subject was shown one of three versions of six critical items, one of which did not depict the critical event item. The critical items consisted of a coffee jar (Folgers, Maxwell House, or blank), a pack of cigarettes (Marlboro, Winston, or blank), a magazine (Glamour, Vogue, or blank), a mug with an initial ( $R$, $M$, or blank), a soda can (7-Up, Sunkist, or blank), and a tool (screwdriver, wrench, or blank). The blank slides, for all items except the pack of cigarettes, were nearly identical to the critical slides that depicted event items, except that the critical event items were not shown. For the pack of cigarettes, the blank version involved showing the preceding slide (which depicted the man reaching into his shirt pocket) twice in succession. Each subject was shown three critical event items (shown-event-item condition) and three blank slides (not-shown-event-item condition). Counterbalancing ensured that, for any critical item type, each version of the event items was shown equally often to the subjects.

The narrative. In the narrative, each subject was presented with (1) one postevent item that contradicted a shown event item and one postevent item that mentioned a detail not shown in the slides (misled condition), (2) neutral information (e.g., tool) regarding one shown event item and one not-shown event item (neutral control), and (3) no information regarding one shown event item and one not-shown event item (pure control). The Appendix lists the sentences used to create misled, neutral control, and pure control conditions. Counterbalancing ensured that all possible versions of postevent sentences were used equally often.

Recall test. Instructions informed the subjects that the narrative may have provided consistent, inconsistent, or no information regarding particular details in the event, using as an example a Hochschild's shopping bag that had appeared in one of the slides. Each subject was asked to answer the same 10 questions, 6 of which dealt with critical items and 4 of which were fillers. With respect to the critical item questions, each subject was queried about (1) a pure control event item (pure control/shown-event-item condition), (2) a pure control blank slide (pure control/not-shown-event-item condition), (3) a neutral control event item (neutral control/shownevent-item condition), (4) a neutral control blank slide (neutral control/not-shown-event-item condition), (5) a misinformation target event item (misled/shown-event-item condition), and (6) a misinformation target blank slide (misled/not-shown-event-item condition). With regard to the 4 filler questions, 3 referred to items about which the narrative provided consistent information and one referred to an item about which no information had been presented in the narrative. As with Experiment 1, the subjects were instructed to report two different answers if they remembered contradictory information from the event and the postevent narrative; they were instructed to report the same answer twice if they remembered consistent information from the two sources. Also as in Experiment 1, guessing was encouraged.

\section{Results and Discussion}

There was one item in each of the six conditions for each of the 288 subjects. For each condition, the recall frequencies of the various item types are presented in Table 3. Overall, of the 864 opportunities to report event items shown in the slides, the subjects did so on $280 \mathrm{oc}$ casions (32.4\% of the time); the subjects reported postevent items $71.0 \%(409 / 576)$ of the time.

\section{Memory Impairment}

To test whether exposure to misinformation reduced the number of event item recalls, the event item responses in the shown-event conditions were compared against the guessing rates of event items in the not-shown event conditions. Two 2 (event item shown vs. not shown) $\times 3$ (pure control vs. neutral control vs. misled) repeated measures analyses of variance (ANOVAs) were conducted, one with subjects treated as a random effect $(F)$ and the second with items treated as a random effect $\left(F^{\prime}\right)$. In both analyses, scores for guessing correctly in the not-shownevent-item conditions were based on the likelihood that a response would be correct if an actual event item was shown. In the pure control/not-shown-event-item and neutral control/not-shown-event-item conditions, a guessed response of an event item was awarded a score of .5, because either guess would be correct only half of the time since there were two possible event items. ${ }^{6}$ In the $\mathrm{misled} /$ not-shown-event-item condition, the subjects received a score of 1 if they guessed the event item that had not been presented to them as the postevent item. In the items analysis, the total number of event item re- 
Table 3

Contingency Tables of the Number of the Types of Items Reported as First and Second Responses in the Conditions of Experiment 3

\begin{tabular}{|c|c|c|c|c|c|}
\hline \multirow[b]{2}{*}{ Condition } & \multirow{2}{*}{$\begin{array}{c}\text { Second } \\
\text { Response }\end{array}$} & \multicolumn{4}{|c|}{ First Response } \\
\hline & & Event & Possible* & Extraneous $\ddagger$ & Blank \\
\hline \multirow[t]{6}{*}{ Pure Control/Shown } & Event & 2 & & 1 & \\
\hline & $\begin{array}{l}\text { Possible* } \\
\text { Extraneous } \ddagger\end{array}$ & & 1 & 2 & \\
\hline & 2nd Extra $\$$ & & & 2 & \\
\hline & Blank & 96 & 22 & 46 & 116 \\
\hline & & \multicolumn{4}{|c|}{ First Response } \\
\hline & & Event & Possible* & Extraneous $\ddagger$ & Blank \\
\hline \multirow[t]{7}{*}{ Neutral Control/Shown } & Event & 6 & & 2 & \\
\hline & Possible* & & 1 & & \\
\hline & Extraneous $\ddagger$ & 1 & & 1 & \\
\hline & 2nd Extra. $\S$ & & & 1 & \\
\hline & Blank & 97 & 15 & 44 & 120 \\
\hline & & \multicolumn{4}{|c|}{ First Response } \\
\hline & & Event & Postevent & Extraneous $\ddagger$ & Blank \\
\hline \multirow[t]{6}{*}{ Misled/Shown } & Event & 5 & 8 & & \\
\hline & Postevent & 39 & 33 & 3 & \\
\hline & Extraneous $\ddagger$ & 3 & 1 & & \\
\hline & Blank & 20 & 117 & 17 & 42 \\
\hline & & \multicolumn{4}{|c|}{ First Response } \\
\hline & & Possible* & Extr & aneous $\ddagger$ & Blank \\
\hline \multirow[t]{7}{*}{ Pure Control/Not Shown } & Possible* & 1 & & & \\
\hline & 2nd Possible* & 2 & & & \\
\hline & Extraneous $\$$ & 2 & & 2 & \\
\hline & 2nd Extra. $\$$ & & & 1 & \\
\hline & Blank & 38 & & 53 & 189 \\
\hline & & \multicolumn{4}{|c|}{ First Response } \\
\hline & & Possible* & Extr & aneous & Blank \\
\hline \multirow[t]{6}{*}{ Neutral Control/Not Shown } & Possible* & 1 & & 2 & \\
\hline & $\begin{array}{l}\text { 2nd Possible } \dagger \\
\text { Extraneous } \ddagger\end{array}$ & & & & \\
\hline & 2nd Extra. $\S$ & & & 1 & \\
\hline & Blank & 43 & & 61 & 180 \\
\hline & & \multicolumn{4}{|c|}{ First Response } \\
\hline & & Postevent & Possible* & Extraneous $\neq$ & Blank \\
\hline \multirow[t]{4}{*}{ Misled/Not Shown } & Postevent & 25 & 1 & 4 & \\
\hline & Possible $†$ & 2 & 1 & & \\
\hline & Extraneous $¥$ & 1 & 1 & 1 & \\
\hline & Blank & 175 & 14 & 22 & 41 \\
\hline
\end{tabular}

Note-Subjects provided up to two responses per question, a first response (if any) and a second response (if any). If subjects wrote the same item twice, the same item is reported as first and second responses. *Possible responses are those that would have been either event or postevent items in other conditions; provides guessing rate estimates on reporting these items when not exposed to them. TSecond possible responses refers to a different possible item provided with the second response. †Extraneous responses are reports of items that did not serve in any conditions as event or postevent items. §Second extraneous responses refers to a different extraneous item provided with the second response.

sponses for each item, out of a possible 24 ( 2 versions of each of 6 objects, with 2 subjects seeing each as event details), was computed for all conditions.

In reports of event items as first or second responses (or both) as the dependent measure, both ANOVAs reveal a significant difference among the pure control (subjects, $M=.21$; items, $M=5.06$ ), neutral control (sub- jects, $M=.22$; items, $M=5.37$ ), and misled (subjects, $M=.16$; items, $M=3.92)$ conditions $[F(2,574)=5.23$, $M S_{\mathrm{e}}=.11, p=.006 ; F^{\prime}(2,22)=6.33, M S_{\mathrm{e}}=2.24$, $p=.007]$ and a significant difference between shownevent (subjects, $M=.32$; items, $M=7.78$ ) and notshown-event (subjects, $M=.07$; items, $M=1.79$ ) conditions $\left[F(1,287)=202.53, M S_{\mathrm{e}}=.13, p<.0001\right.$; 
$\left.F^{\prime}(1,11)=33.42, M S_{\mathrm{e}}=19.30, p<.001\right]$. Most importantly, an interaction effect approached statistical significance with the subjects analysis and was statistically significant with the items analysis $[F(2,574)=2.41$, $M S_{\mathrm{e}}=.14, p=.09 ; F^{\prime}(2,22)=3.48, M S_{\mathrm{e}}=2.38$, $p<.05]$.

To gain an appreciation of the interaction effect, Figure 1 illustrates the percent of event item responses in all conditions. As suggested by Figure 1, there was a significant simple effect among the pure control, neutral control, and misled conditions when the subjects were shown event items $\left[F(2,574)=4.29, M S_{\mathrm{e}}=.21, p<.02\right.$; $\left.F^{\prime}(2,22)=6.55, M S_{\mathrm{e}}=3.36, p<.01\right]$, but there were no differences among these conditions in guessing event items when the subjects were not shown these items (both $F$ and $F^{\prime}<1$ ). Additional comparisons reveal that with shown event items, both control conditions differed significantly from the misled condition [pure control/shownevent-item vs. misled/shown-event-item condition, $F(1,287)$

$=4.95, M S_{\mathrm{e}}=.20, p<.03$, and $F^{\prime}(1,11)=7.76$, $M S_{\mathrm{e}}=3.09, p<.02 ;$ neutral control/shown-event-item vs. misled/shown-event-item conditions, $F(1,287)=$ $8.14, M S_{\mathrm{e}}=.20, p<.01$, and $F^{\prime}(1,11)=7.80, M S_{\mathrm{e}}=$ $5.13, p<.02$ ], but the pure and neutral control conditions did not differ $\left(F=0.36 ; F^{\prime}=1.10\right)$.

These results support memory impairment, as they show in the misled condition, relative to both control conditions, misinformation effects that cannot be accounted for by differential guessing among conditions. In addition, because the subjects were encouraged to guess, the results support an impairment explanation-that is, misinformation hindering the ability to remember the event-rather than an explanation based on differential response criteria. Finally, the results provide no support for the retention enhancement hypothesis, because the subjects in the pure and neutral control conditions performed equally well.

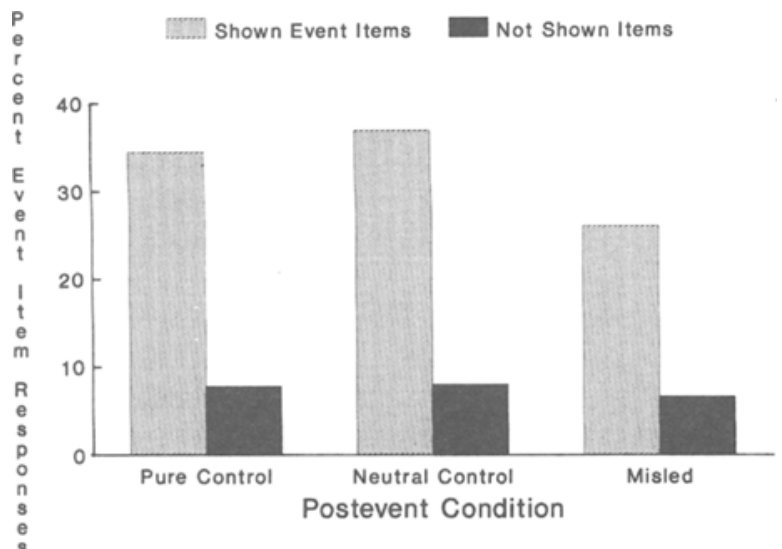

Figure 1. Percent of event item recalls when the subjects were shown event items, and percent of guessing event items when they were not shown event items for the pure control, neutral control, and misled conditions of Experiment 3.

\section{Proactive Interference}

The design of Experiment 3 provides an opportunity to test for proactive interference-that is, to determine if being exposed to event items interfered with the ability to remember postevent items. There was no evidence for proactive interference. Using postevent item response as first or second response (or both) as a dependent variable in subjects analyses, both a postevent condition (pure control vs. misled) $\times$ event item (shown vs. not shown) repeated measures ANOVA and a postevent condition (neutral control vs. misled) $\times$ event item (shown vs. not shown) repeated measures ANOVA revealed only that being exposed to postevent items led to more frequent reports of postevent items (misled, $M=.71$ ) relative to guessing postevent items with either the pure control $\left[M=.08 ; F(1,287)=836.25, M S_{\mathrm{e}}=.14, p<\right.$ $.0001]$ or the neutral control $[M=.07 ; F(1,287)=$ $\left.868.10, M S_{\mathrm{e}}=.14, p<.0001\right]$ condition. Neither analysis indicated that being shown event items reduced the ability to report postevent items; there was no main effect for event item (both $F \mathrm{~s} \leq 1.48$ ), nor was there a postevent condition $\times$ event item interaction effect (both Fs $<1)$.

One factor that has been shown to mediate interference is the retrievability of the interfering item (e.g., Barnes \& Underwood, 1959). The greater the ability to report the interfering item, the less likely the target item will be reported. In general, the conditions of Experiment 3 led to higher report rates of postevent items than of event items. We speculate that memory impairment (retroactive interference) occurred because the interfering postevent items were more accessible than were the target event items; on the other hand, proactive interference did not occur because the event items were less accessible than were the postevent items.

\section{Source Misattribution}

As in both Experiments 1 and 2, Experiment 3 revealed source misattributions. Examination of pure control/ shown-event-item, neutral control/shown-event-item, misled/shown-event-item, and misled/not-shown-eventitem conditions revealed 71 instances in which the subjects reported having both seen and read either event or postevent items by writing the same item as both first and second responses (see Table 3). In addition, similar to the trends seen in Experiments 1 and 2, there was a greater tendency to report having seen postevent items at the event than to report having read event items. Out of 409 postevent item responses, $58(14 \%)$ involved reporting the item twice; out of 280 event item responses, $13(5 \%)$ involved reporting the item twice. An items analysis revealed that there was indeed a greater tendency to report both having seen and read postevent items (which were only read; $M=.14, S D=.09$ ) than to both having seen and read event items (which were only seen; $M=.03$, $S D=.05)[t(11)=4.61, p=.001]$. 


\section{EXPERIMENT 4}

Taken together, the findings of Experiments 1-3 are supportive of the presence of memory impairment. However, the statistical tests reveal a number of instances, particularly with some subjects analyses, in which results are only marginally significant. To provide greater confidence in the reliability of the findings, Experiment 4 was conducted as an attempt to replicate the important results supportive of memory impairment that were found in Experiment 3.

In Experiments 1-3, we might have had difficulty in obtaining statistically reliable findings with subjects analyses because the counterbalancing schemes used in the experiments were likely to have compromised the ability to detect impairment. Some event items are better recalled than others. Through counterbalancing, some subjects are presented with misinformation target items that are easier to recall than their corresponding control items. As an example, data from the shown conditions in Experiment 3 reveal that the tool item types were reported much more often ( $43 \%$ of the total opportunities) than were the soda can item types (only $8 \%$ of the time). Thus, the subjects who received a tool as a misinformation target item and a soda can as a control item would more likely have been able to report the tool than to report the soda can. The end result is that a considerable number of subjects would have better recall for misinformation target items, despite the fact that memory impairment might have occurred. To be in a better position to detect memory impairment in subjects analyses in Experiment 4, we presented only sets of control and misinformation target items to subjects that, on the basis of the data in Experiment 3, would be fairly equivalent in recallability.

\section{Method}

Subjects

The subjects were 64 undergraduates ( 34 women and 30 men) at Xavier University who participated for credit in an introductory level psychology course. The ages ranged from 18 to 41 years $(M=$ 20.8 ). The subjects were tested in groups that varied in size from 2 to 10 .

\section{Procedure}

The procedure was identical to that of Experiment 3, except for the following differences:

The slides and narrative. All subjects saw the same slides, except that showing or not showing event items was treated as a between-subjects factor. Forty subjects were shown six critical event items; 24 subjects were not shown any critical event items-they were presented with the six blank versions of slides that were used in Experiment 3. For the subjects shown the critical items, four postevent narratives were created such that, on the basis of the data of Experiment 3, each subject received sets of control and misinformation target items equivalent in overall recallability. Specifically, one fourth of the subjects who were shown critical items received Maxwell House, Winston, and Sunkist as control items, with Glamour, the initial $\mathrm{M}$, and screwdriver as misinformation target items (and thus were misled with a narrative that used Vogue, the initial $\mathbf{R}$, and wrench as postevent items). One fourth received Glamour, the initial M, and screwdriver as control items, with Maxwell House, Winston, and Sunkist serving as misinformation tar- get items. One fourth had Marlboro, Vogue, and the initial $\mathrm{R}$ as control items, with Folgers, 7-Up, and wrench as misinformation target items. Finally, one fourth received Folgers, 7-Up, and wrench as control items, with Marlboro, Vogue, and the initial $\mathbf{R}$ serving as misinformation target items. For control items, the narrative used only the pure control sentences used in Experiment 3 (see the Appendix), such that no neutral information was provided. The subjects who were not shown critical event items were given the same four narratives that were provided to the subjects who were shown critical event items, such that one fourth of these subjects were given one of the narrative types. Given that all subjects received misleading postevent information, control versus misled condition was manipulated within subjects. The design permitted all versions of critical items to serve as control, misinformation target, and postevent items equally often.

Recall test. All subjects received the same recall test with the same 10 questions and the same instructions as those used in Experiment 3 . Depending on condition, the questions formed different types. Specifically, for the subjects who were shown critical event items, 4 questions dealt with items that were shown in the slides but to which the narrative mentioned nothing ( 1 filler and 3 critical questions), 3 dealt with event items that were contradicted in the narrative (all critical questions), and 3 dealt with items shown in the slides to which the narrative provided consistent information (all filler questions). For the subjects who were not shown critical items, 3 of the questions asked about item types that were neither shown in the slides nor presented in the narrative (control condition questions), 3 asked about items only presented in the narrative (misled condition questions), 1 filler question asked about a type of item shown only in the slides, and-identical to those for the subjects shown event items-the remaining 3 filler questions were of the consistent variety.

\section{Results and Discussion}

The recall frequencies of the various item types are presented in Table 4 separately for the pure control/shownevent-item, misled/shown-event-item, pure control/notshown-event-item, and misled/not-shown-event-item conditions. The subjects reported event items 84 out of the 240 opportunities to do so (35.0\% of the time); they reported postevent items $75.5 \%(145 / 192)$ of the time.

\section{Memory Impairment}

Two slides condition (event items shown vs. not shown) $\times$ postevent information condition (pure control vs. misled) ANOVAs were conducted, one with subjects treated as a random effect $(F)$ and the second with items treated as a random effect $\left(F^{\prime}\right)$, in order to test for the presence of memory impairment. In both analyses, reports of event items as first or second responses were used as the dependent measure, and scores for guessing correctly in the not-shown-event-item conditions were based on the likelihood that a response would be correct if an actual event item was shown, according to the same scoring scheme as used in Experiment 3. In the subjects analysis, the total number of event item recalls, out of a possible three per control and misled conditions, was used. Slides were treated as a between-subjects factor, and postevent information was a within-subjects factor. In the items analysis, since there were an unequal number of subjects between shown and not-shown conditions, the total number of possible event item responses was not identical between these conditions (for each item, there were 
Table 4

Contingency Tables of the Number of the Types of Items Reported as First and Second Responses in the Conditions of Experiment 4

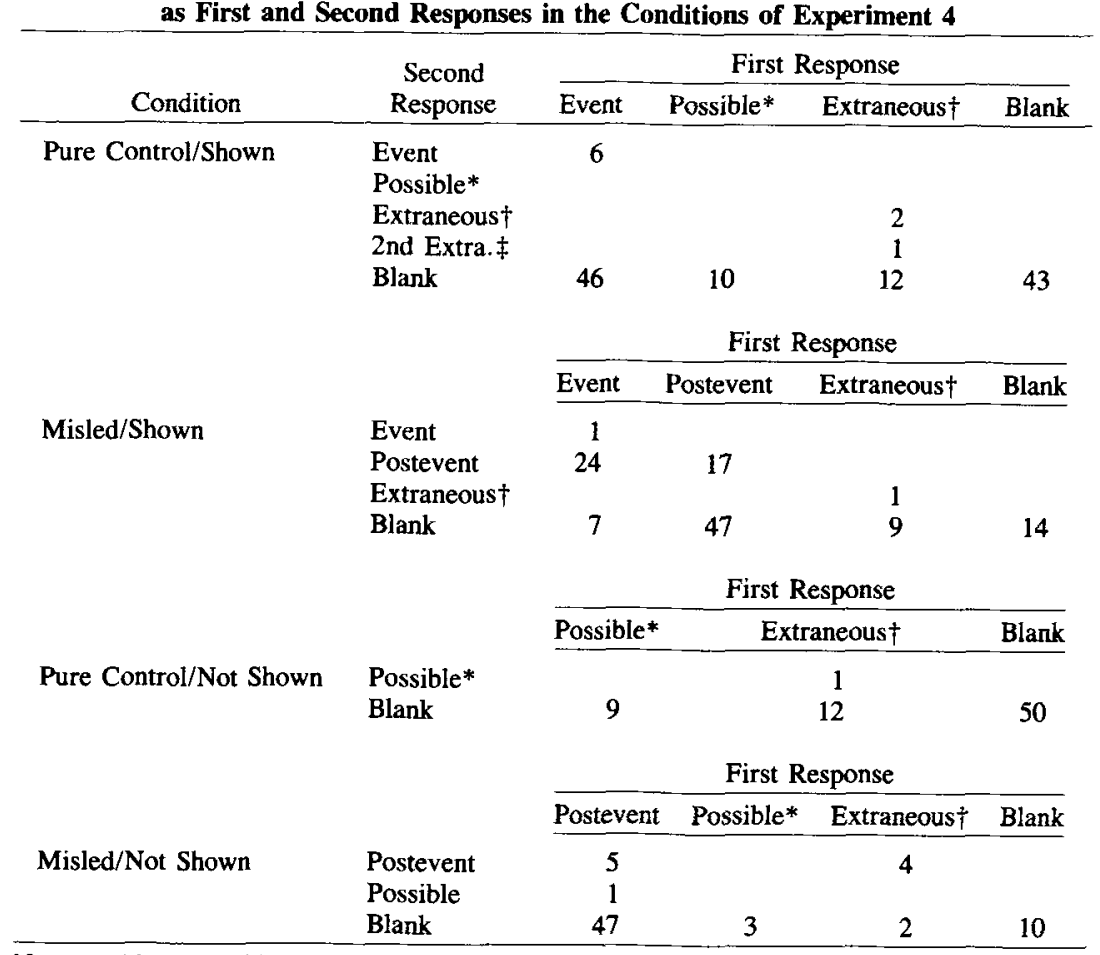

Note-Subjects provided up to two responses per question, a first response (if any) and a second response (if any). If subjects wrote the same item twice, the same item is reported as first and second responses. *Possible responses are those that would have been either event or postevent items in other conditions; provides guessing rate estimates on reporting these items when not exposed to them. †Extraneous responses are reports of items that did not serve in any conditions as event or postevent items. ‡Second extraneous responses refers to a different extraneous item provided with the second response.

10 possible event item responses in the shown conditions, and 6 possible event item responses in the not-shown conditions). Thus, the proportions of event item responses to the total possible were used in the items analysis. Both slides and postevent information were treated as withinitems factors.

The results are consistent with those obtained in Experiment 3. Both ANOVAs reveal a significant difference in event item responses between the pure control (subjects, $M=0.88$; items, $M=.25$ ) and misled (subjects, $M=0.56$; items, $M=.16)$ conditions $[F(1,62)=4.97$, $M S_{\mathrm{e}}=.41, p=.03 ; F^{\prime}(1,11)=5.45, M S_{\mathrm{e}}=.02, p=$ $.04]$ and a significant difference between the shown-eventitem (subjects, $M=1.05$; items, $M=.35$ ) and notshown-event-item (subjects, $M=0.18$; items, $M=.06$ ) conditions $\left[F(1,62)=40.08, M S_{e}=.56, p<.001\right.$; $\left.F^{\prime}(1,11)=33.28, M S_{\mathrm{e}}=.03, p<.001\right]$. Importantly, the interaction effect was significant in both analyses with $F(1,62)=4.21, M S_{\mathrm{e}}=.41, p<.05$, and with $F^{\prime}(1,11)=6.10, M S_{\mathrm{e}}=.01, p=.03$.

Figure 2 illustrates the percent of event item responses in the four conditions. As shown in Figure 2, there was a significant simple effect between the pure control and misled conditions when the subjects were shown event items $\left[F(1,39)=8.48, M S_{e}=.59, p<.01 ; F^{\prime}(1,11)=\right.$
$6.04, M S_{\mathrm{e}}=.03, p=.03$ ], but there were no differences between these conditions in guessing event items when the subjects were not shown the items (both $F$ and $F^{\prime}<$ 1). These results replicate the findings of Experiment 3 in support of memory impairment.

\section{Proactive Interference}

Consistent with the results of Experiment 3, the results of Experiment 4 show no evidence for proactive interference. A slides condition (event items shown vs. not shown) $\times$ postevent information condition (pure control vs. misled) subjects analysis, with postevent item response as a dependent variable, shows only that being exposed to postevent items led to more frequent reports of postevent items (misled, $M=2.28$ ) relative to guessing postevent items [control, $M=.23 ; F(1,62)=253.49, M S_{\mathrm{e}}=.51$, $p<.0001]$. The analysis showed no difference in the subjects' ability to report postevent items when shown and not shown event items, and there was no slides condition $\times$ postevent item interaction effect (both $F \mathrm{~s}<1$ ).

\section{Source Misattribution}

The results of Experiment 4 are consistent with those of Experiments 1-3 in revealing source misattributions. Of the 84 reports of event items in the shown conditions, 


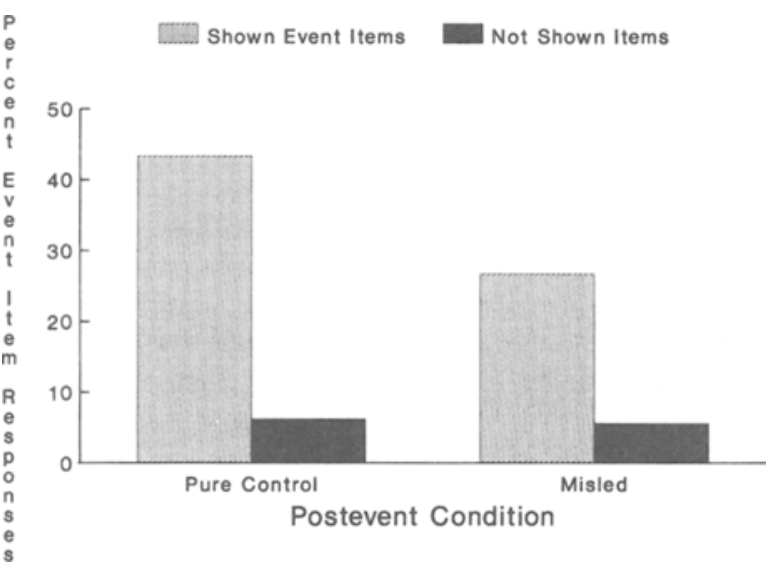

Figure 2. Percent of event item recalls when the subjects were shown event items, and percent of guessing event items when they were not shown event items for the pure control and misled conditions of Experiment 4.

$7(8.3 \%)$ were instances in which the subjects reported having both seen and read the event items; of the 145 reports of postevent items, $22(15.1 \%)$ in the misled conditions were instances in which the subjects claimed to have both seen and read the postevent items (see Table 4). Although this is a trend in the same direction as seen in Experiments 1-3, in which there was a greater tendency to report both having seen and read postevent items $(M=$ $.15, S D=.11)$ than to report having seen and read event items $(M=.08, S D=.06)$, an items analysis was not significant $[t(5)=1.30, p=.25]^{7}$

\section{GENERAL DISCUSSION}

Four experiments tested whether the introduction of misleading postevent information can impair the ability to remember an original event on a recall test with a short retention interval. In all four experiments, misinformation effects were found, supporting the memory impairment hypothesis. Also found in these results was evidence for memory impairment when the subjects were encouraged (Experiments 1, 3, and 4) and not encouraged (Experiment 2) to guess and when the subjects were asked (Experiment 2) and not asked (Experiments 1, 3, and 4) to locate the sources of items that they remembered. Alternatives to memory impairment were ruled out; differential guessing and retention enhancement hypotheses were directly tested and found not to be totally responsible for the poorer misled memory of items shown at the event, relative to control memory of items shown at the event.

Our results also shed light on the question of misled subjects' phenomenal experience at test. The subjects often reported that they had seen the suggested details in the slides. As noted above, when the standard suggestibility procedure is used there are a number of reasons why subjects might make such claims without actually having the subjective experience of remembering seeing those details (e.g., they may trust the postevent narrative and wish to show that they are good subjects who paid close attention to the slides). In the present experiments, however, such demand characteristics were minimized. The subjects knew that the narrative included misleading suggestions. Consequently, memories of the narrative could not have served as reliable bases for inferences about what a "good"' subject would remember from the slides. Also, the form of the questions in Experiment 2 (which specifically asked the subjects what they remembered seeing in the slides and what they remembered reading in the narrative) oriented the subjects to be vigilant about the sources of their memories; such vigilance reduces the likelihood that subjects will claim to have seen an object simply because it is familiar from the experiment (Lindsay \& Johnson, 1989; Zaragoza \& Koshmider, 1989; Zaragoza \& Muench, 1988). Finally, the subjects were given an opportunity to demonstrate their knowledge of information presented in the story without having to claim that they remembered seeing that information in the slides. Thus, it is unlikely that the subjects who reported that they had seen a suggested detail in the slides knew that their memory of that detail was derived only from the narrative.

The experiments also provide evidence for asymmetries in source monitoring errors, paralleling other research on source monitoring (Anderson, 1984; Foley, Durso, Wilder, \& Friedman, 1991; see Johnson, Hashtroudi, \& Lindsay, 1993, for a comprehensive review). In general, subjects are more likely to mistakenly attribute a memory derived from the postevent narrative to the event than to mistakenly attribute a memory from the event to the narrative. Presumably, subjects are more likely to form visual images of the event while reading the narrative than they are to form text-like images while viewing the visual event, so memories of reading are likely to have characteristics typical of viewing the event, whereas memories of viewing the event are unlikely to have characteristics typical of reading the narrative.

\section{Generalizability of Memory Impairment}

The present experiments extend our knowledge concerning the conditions in which memory impairment occurs. Strong evidence for memory impairment, which has largely depended on finding misinformation effects with the modified test procedure (McCloskey \& Zaragoza, 1985), has been found with experiments that have used long retention intervals and centrally presented event items (Belli et al., 1992; Ceci et al., 1987; Toglia et al., 1992; cf. Lindsay, 1990), but not with experiments that have used short retention intervals and peripherally presented event items (Belli, 1993; Bonto \& Payne, 1991; E. F. Loftus et al., 1989; McCloskey \& Zaragoza, 1985; Zaragoza, 1987; Zaragoza, 1991). In the present experiments, memory impairment has been shown to occur under these latter conditions.

A number of experiments using short retention intervals (E. F. Loftus, 1975; E. F. Loftus et al., 1989; E. F. Loftus et al., 1978; McCloskey \& Zaragoza, 1985) have found robust misinformation effects with test procedures that allow postevent items as responses; however, because 
these tests were unable to rule out alternative explanations, whether memory impairment has been at all responsible for the observed effects has been in doubt. The present short retention interval experiments, by controlling for alternative explanations, suggest that memory impairment contributed to the misinformation effects found in those short retention experiments that permitted postevent items as response options. It is likely that a substantial portion of the standard misinformation effect is due to the sorts of guessing and response biases suggested by McCloskey and Zaragoza (1985), but that genuine memory impairment also plays a role in such effects.

Thus, memory impairment is a widespread phenomenon that appears in a range of conditions (cf. Chandler, 1989, 1991). In addition, other evidence has shown memory impairment with a range of subject populations, including adults (Belli et al., 1992; Lindsay, 1990), preschool children (Ceci et al., 1987; Toglia et al., 1992), and even preverbal infants (Greco, Hayne, \& Rovee-Collier, 1990; Rovee-Collier, Borza, Adler, \& Boller, 1993). The evidence suggests that eyewitnesses in a variety of situations may be susceptible to memory impairment by postevent misinformation.

\section{Mechanisms of Memory Impairment}

Although there is now substantial evidence that memory impairment occurs, we can only speculate on responsible mechanisms. Since there is a dissociation between tests that do and do not permit the postevent item response option in finding impairment in experiments with short retention intervals, a reasonable hypothesis is that the mechanisms responsible for impairment with these different test procedures are not the same.

In experiments that employ peripheral event items with short retention intervals, memories of the postevent items are likely to be more accessible than memories of the event items because they are presented closer to the time of the test and may be better encoded due to their relatively focal and distinctive presentation in the narrative relative to the details in the event. Thus, at test, memories of postevent items are likely to be retrieved first. In tests that permit the postevent option, subjects who gain access to the postevent item may be satisfied that this item was in the event and may therefore terminate memory search. Note that this impairment mechanism involves source misattribution, either in the sense that subjects simply accept the postevent item as having been in the event or in the sense that they genuinely "remember" seeing the postevent item in the event. In support of this impairment mechanism, E. F. Loftus et al. (1989) found very quick and confident selection of postevent items at test among subjects in the misled condition when tested with the standard test. With tests that do not permit the postevent option, subjects who gain access to memories of the postevent item will note that it is not a response option and may consequently continue searching memory, eventually gaining access to memories of event items. In support of this notion of continuing search, E. F. Loftus et al. (1989) found that, with the modified test, subjects take longer to make an event item selection on misinformation target items than on control items.

Relative to tests that permit postevent items as responses, in order to detect misinformation effects with tests that exclude the postevent item, the impairment must be more entrenched. Experiments that use centrally presented event items and long retention intervals may enhance memory impairment by presenting the postevent item closer to the time of test than to the time of the event, thereby making memories of the postevent item much more accessible than memories of the event item at test. Perhaps the postevent item actually blocks access to the event item in these conditions (see Belli et al., 1992; Chandler, 1991; Lindsay, 1990), although experiments designed to test the blocking hypothesis have not provided support (Belli, 1993). Other possibilities include storagebased impairment, in which the postevent misinformation actually degrades the original trace of the event information, perhaps through an interaction of suggestibility and retention interval in which some passage of time after viewing the event is necessary to detect the impairing effects of misinformation (see Belli et al., 1992; Brainerd \& Reyna, 1988).

\section{Conclusion}

Since McCloskey and Zaragoza (1985) published their critique of evidence for the memory impairment hypothesis, researchers have been uncertain whether misinformation effects are due to memory impairment or other processes. At this point, it is clear that although processes such as guessing and response biases contribute to such effects, genuine memory impairment also plays an important role. Our findings support the hypotheses that misleading suggestions impair memory for visual events and that misled subjects sometimes genuinely believe that they have seen suggested details in the visual event. With regard to memory impairment and source misattribution, their occurrence is no longer in doubt. Attention can now be paid to determining more precisely the different forms that these processes can assume and the variables that affect their magnitude.

\section{REFERENCES}

ANDERSON, R. E. (1984). Did I do it or did I only imagine doing it? Journal of Experimental Psychology: General, 113, 594-613.

BarNes, J. M., \& UNDerwood, B. J. (1959). "Fate" of first-list associations in transfer theory. Journal of Experimental Psychology, 58, 97-105.

BeKERIAN, D. A., \& Bowers, J. M. (1983). Eyewitness testimony: Were we misled? Journal of Experimental Psychology: Learning, Memory, \& Cognition, 9, 139-145.

BELLI, R. F. (1989). Influences of misleading postevent information: Misinformation interference and acceptance. Journal of Experimental Psychology: General, 118, 72-85.

BELLI, R. F. (1993). Failure of interpolated tests in inducing memory impairment with final modified tests: Evidence unfavorable to the blocking hypothesis. American Journal of Psychology, 106, 407-427. BeLli, R. F., Windschitl, P. D., McCarthy, T. T., \& Winfrey, S. E. (1992). Detecting memory impairment with a modified test pro- 
cedure: Manipulating retention interval with centrally presented event items. Journal of Experimental Psychology: Learning, Memory, \& Cognition, 18, 356-367.

Bonto, M. A., \& PAyne, D. G. (1991). Role of environmental context in eyewitness memory. American Journal of Psychology, 104, 117-134.

Brainerd, C. J., Reyna, V. F. (1988). Memory loci of suggestibility development: Comment on Ceci, Ross, and Toglia (1987). Journal of Experimental Psychology: General, 117, 197-200.

CeCl, S. J., Ross, D. F., \& Toglia, M. P. (1987). Suggestibility in children's memory: Psycholegal implications. Joumal of Experimental Psychology: General, 116, 38-49.

ChandLer, C. C. (1989). Specific retroactive interference in modified recognition tests: Evidence for an unknown cause of interference. Journal of Experimental Psychology: Learning, Memory, \& Cognition, 15, 256-265.

Chandler, C. C. (1991). How memory for an event is influenced by related events: Interference in modified recognition tests. Journal of Experimental Psychology: Learning, Memory, \& Cognition, 17, 115-125.

Christiansen, R. E., \& Ochalek, K. (1983). Editing misleading in formation from memory: Evidence for the coexistence of original and post-event information. Memory \& Cognition, 11, 467-475.

Foley, M. A., Durso, F. T., Wilder, A., Friedman, R. (1991). Developmental comparisons of explicit versus implicit imagery and reality monitoring. Journal of Experimental Child Psychology, 51 , $1-13$.

Greco, C., Hayne, H., \& Rovee-Collier, C. (1990). Roles of function, reminding, and variability in categorization by 3 -month-old infants. Journal of Experimental Psychology: Learning, Memory, \& Cognition, 16, 617-633.

Johnson, M. K., Hashtroudi, S., LindSAY, D. S. (1993). Source monitoring. Psychological Bulletin, 114, 3-28.

Johnson, M. K., LinDSAY, D. S. (1986). Despite McCloskey and Zaragoza, suggestibility effects may reflect memory impairment. Unpublished manuscript, Princeton University, Department of Psychology.

LiNDSAY, D. S. (1990). Misleading suggestions can impair eyewitnesses' ability to remember event details. Joumal of Experimental Psychology: Learning, Memory, \& Cognition, 16, 1077-1083.

LINDSAY, D. S. (in press). Memory source monitoring and eyewitness testimony. In D. F. Ross, J. D. Read, \& M. P. Toglia (Eds.), Adult eyewitness testimony: Current trends and developments. New York: Cambridge University Press.

LINDSAY, D. S., \& JohNSON, M. K. (1989). The eyewitness suggestibility effect and memory for source. Memory \& Cognition, 17 349-358.

LindSAY, D. S., \& Johnson, M. K. (1991). Recognition memory and source monitoring. Bulletin of the Psychonomic Society, 29, 203-205.

LofTus, E. F. (1975). Leading questions and the eyewitness report. Cognitive Psychology, 7, 560-572.

LofTus, E. F. (1992). When a lie becomes memory's truth: Memory distortion after exposure to misinformation. Current Directions in Psychological Science, 1, 121-123.

Loftus, E. F., Donders, K., Hoffman, H. G., \& Schooler, J. W. (1989). Creating new memories that are quickly accessed and confidently held. Memory \& Cognition, 17, 607-616.

LoFTUS, E. F., \& LoFTUS, G. R. (1980). On the permanence of stored information in the human brain. American Psychologist, 35, 409-420.

LofTus, E. F., Miller, D. G., \& Burns, H. J. (1978). Semantic integration of verbal information into a visual memory. Journal of $E x$ perimental Psychology: Human Learning \& Memory, 4, 19-31.

McCloskey, M., Zaragoza, M. (1985). Misleading postevent information and memory for events: Arguments and evidence against memory impairment hypotheses. Joumal of Experimental Psychology: General, 114, 1-16.

Rovee-Collier, C., Borza, M. A., Adler, S. A., \& Boller, K. (1993). Infants' eyewitness testimony: Integrating postevent information with a prior memory representation. Memory \& Cognition, 21, 267-279.

Toglia, M. P., Ross, D. F., Ceci, S. J., \& Hembrooke, H. (1992).
The suggestibility of children's memory: A social-psychological and cognitive interpretation. In M. L. Howe, C. J. Brainerd, \& V. F. Reyna (Eds.), Development of long-term retention (pp. 217-241). New York: Springer-Verlag.

TVersky, B., \& TuCHIN, M. (1989). A reconciliation of the evidence on eyewitness testimony: Comments on McCloskey and Zaragoza. Journal of Experimental Psychology: General, 118, 86-91.

ZARAGOZA, M. S. (1987). Memory, suggestibility, and eyewitness testimony in children and adults. In S. J. Ceci, M. P. Toglia, \& D. F. Ross (Eds.), Children's eyewitness memory (pp. 53-78). New York: Springer-Verlag.

Zaragoza, M. S. (1991). Preschool children's susceptibility to memory impairment. In J. Doris (Ed.), The suggestibility of children's recollections (pp. 27-39). Washington, DC: American Psychological Association.

Zaragoza, M. S., Dahlgren, D., \& Muench, J. (1992). The role of memory impairment in children's suggestibility. In M. L. Howe, C. J. Brainerd, \& V. F. Reyna (Eds.), Development of long-term retention (pp. 184-213). New York: Springer-Verlag.

Zaragoza, M. S., \& Koshmider, J. W., III (1989). Misled subjects may know more than their performance implies. Joumal of Experimental Psychology: Learning, Memory. \& Cognition, 15, 246-255.

ZARAGOZA, M. S., \& LANE, S. (1992). Misinformation and memory impairment: Evidence from a modified modified free recall test. Unpublished manuscript, Kent State University, Department of Psychology.

Zaragoza, M. S., McCloskey, M., \& Jamis, M. (1987). Misleading postevent information and recall of the original event: Further evidence against the memory impairment hypothesis. Joumal of Experimental Psychology: Learning, Memory, \& Cognition, 13, 36-44. Zaragoza, M. S., \& Muench, J. (1988, November). Are misinformation phenomena due to integration? Poster presented at the annual meeting of the Psychonomic Society, Chicago.

\section{NOTES}

1. Chandler $(1989,1991)$ has found misinformation effects with short retention intervals using the modified test. Her experiments, however, lie outside the present discussion since her materials were considerably different than those used in the present experiments, making generalizability difficult. More precisely, it would not be appropriate to characterize her materials as involving peripheral event items, since her event items were pictures of whole nature scenes (e.g., a photograph of a pond).

2 . In the remaining experiments reported in this paper, to create nonguessing-biased stimuli while maintaining proper counterbalancing, we removed one version each of the coffee jar and magazine item types, as well as the guessing-biased items, Coke and hammer. Nescafe and Mademoiselle were removed from these analyses, since they were the poorest remembered versions of the coffee jar and magazine item types. The subanalyses of non-guessing-biased items in Experiment 1 did not include Nescafe and Mademoiselle, in order to provide better comparison of the results across experiments. These subanalyses were not affected by including responses to these two items.

3 . Conducting a subjects analysis with the original data on responses to only these eight non-guessing-biased event items is problematic since some subjects were not shown any of these items as control items or misinformation target items, and some subjects were shown one of these items as a control item but two of these items as misinformation target items, or vice versa. Given these problems, however, we conducted a subjects analysis of the 64 subjects in the main experiment who had been shown at least one non-guessing biased control and misinformation target item. Recalls of event items were given a value of one, otherwise the value of zero was assigned. For cases in which there were responses to two misinformation target items or two control items, the mean value of the correct responses went into the analysis. The subjects analysis confirmed the items analysis with recall of misinformation target items $(M=0.320, S D=0.412)$ to be significantly lower than the recall of control items $[M=0.492, S D=0.467 ; t(63)=2.20$, $p<.02$, one-tailed].

4. Because for some items (e.g., 7-Up) there were no recalls (and computing a proportion becomes meaningless), the items analyses collapsed across all versions of each item type and thus were conducted 
on computations of the proportion of double recalls over total recalls of the coffee jar, magazine, soda can, and tool versions.

5. It is important to note that assignment of filler items to these conditions (slide only vs. slide and story) was not counterbalanced. Thus, the difference in correct responses to these two kinds of items is not interpretable; it may be that the slide-and-story items sometimes functioned as target items, or that reading the slide-and-story items in the story served to remind the subjects of seeing the same details in the slides or that the items assigned to the slide-and-story condition simply happened to be more memorable than the items assigned to the slide-only condition. For present purposes, the important point is that although the subjects were much more successful at answering questions about slide-and-story items than about slide-only items, the frequency of guesses on these two types of items did not differ.

6. In those rare instances $(N=2)$ in which both possible event items were reported, a score of 1 was awarded.

7. Similar to the corresponding items analysis conducted in Experiment 1 , this analysis was conducted by collapsing across both versions of each item type (see Note 4).

\section{APPENDIX}

Sentences Containing Critical Postevent Information for Pure Control, Neutral Control, and Misled Conditions

\section{Item Type/}

Condition

Sentence

Coffee Jar

Pure

The man glanced at the chair, walked over to the file cabinet by the door, and placed his battered tool box on top of the cabinet.

Neutral The man glanced at the chair, walked over to the file cabinet by the door, and moved a yellow coffee pot and a jar of coffee to make room for his battered tool box.

Misled The man glanced at the chair, walked over to the file cabinet by the door, and moved a yellow coffee pot and a jar of (Folgers, Maxwell House) coffee to make room for his battered tool box.

\section{Cigarettes}

Pure

While he was working, he eventually reached over to a round, cream colored ash tray...

Neutral While he was working, he lit a cigarette that he took from his pack in his left shirt pocket.

Misled While he was working, he lit a cigarette that he took from the (Marlboro, Winston) pack in his left shirt pocket.
APPENDIX (Continued)

Item Type/
Condition

\section{Magazine \\ Pure He eventually reached over and put the cigarette out in a round, cream colored ash tray on the end table.}

Neutral He eventually reached over and put the cigarette out in a round, cream colored ash tray next to a magazine on the end table.

Misled He eventually reached over and put the cigarette out in a round, cream colored ash tray next to a (Glamour, Vogue) magazine on the end table.

Initial

Pure He then reached for a silver letter opener.

Neutral He then reached for a silver letter opener sitting in a mug with an initial on it.

Misled He then reached for a silver letter opener sitting in a mug with the initial $(R, M)$ on it.

Soda

Pure As he was doing so, he caught sight of a set of keys sitting on the far side of the desk.

Neutral As he was doing so, he caught sight of a set of keys sitting on the far side of the desk near a can of soda.

Misled As he was doing so, he caught sight of a set of keys sitting on the far side of the desk near a can of (7-Up, Sunkist Orange) soda.

Tool

Pure He stopped at his tool box, opened it, and put the calculator in it.

Neutral He stopped at his tool box, opened it, lifted a tool, and slid the calculator beneath it.

Misled He stopped at his tool box, opened it, lifted a (screwdriver, wrench), and slid the calculator beneath it.

(Manuscript received April 20, 1989; revision accepted for publication June 16, 1993.) 